Supporting Information

\title{
Morphological Evolution of Multilayer Ni/NiO Thin Film Electrodes during Lithiation
}

Guennadi Evmenenko, ${ }^{\dagger}$ Timothy T. Fister, ${ }^{\ddagger}$ D. Bruce Buchholz, ${ }^{\dagger}$ Qianqian Li, ${ }^{\#}$ Kan-Sheng Chen, ${ }^{\dagger}$ Jinsong Wu $,{ }^{+},{ }^{\#}$ Vinayak P. Dravid, ${ }^{\dagger}$ Mark C. Hersam ${ }^{\dagger, \&}$ Paul Fenter, ${ }^{\dagger}$ Michael J. Bedzyk ${ }^{\dagger, *}$

*E-mail: bedzyk@northwestern.edu

${ }^{\dagger}$ Department of Materials Science and Engineering, Northwestern University, Evanston, Illinois 60208, United States

‡Chemical Sciences and Engineering Division, Argonne National Laboratory, Lemont, Illinois 60439, United States

"EPIC, NUANCE Center, Northwestern University, Evanston, Illinois 60208, United States

${ }^{\&}$ Department of Chemistry, Northwestern University, Evanston, Illinois 60208, United States 
Details of multilayer film growth. Nickel - nickel oxide multilayer thin-films were grown by pulsed-laser deposition (PLD). PLD was accomplished with a $248 \mathrm{~nm} \mathrm{KrF}$ excimer laser with a $25 \mathrm{~ns}$ pulse duration and operated at $2 \mathrm{~Hz}$. The laser pulse was focused onto a $1.5 \mathrm{~mm}$ x $2.5 \mathrm{~mm}$ spot size. Nickel was deposited from a metallic nickel target at an energy of $300 \mathrm{~mJ}$ per pulse without the introduction of a reactant gas after the chamber had pumped down to a base pressure of $\sim 5 \times 10^{-7}$ Torr. Nickel oxide was deposited from a dense hot-pressed nickel oxide target at an energy of $200 \mathrm{~mJ}$ per pulse in a deposition ambient of $5 \times 10^{-4}$ Torr UHP oxygen. The targets were rotated at 5-rpm about their axis to prevent localized heating. The target-substrate separation was fixed at $10 \mathrm{~cm}$. The thickness of each layer was controlled by adjusting the number of laser pulses.

Table S1. Tablulated mass density $(\rho)$, calculated electron density $\left(\rho_{\mathrm{e}}\right)$, and critical momentum transfer $\left(q_{\mathrm{c}}\right)$ values of assumed components of the $\mathrm{Ni} / \mathrm{NiO}$ multilayer electrode.

\begin{tabular}{ccccc}
\hline Compound & $\begin{array}{c}\text { Density } \\
\rho\left(\mathrm{g} / \mathrm{cm}^{3}\right)\end{array}$ & $\begin{array}{c}\text { Electron density } \\
\rho_{\mathrm{e}}\left(\mathrm{e}^{-} \AA^{-3}\right)^{* *}\end{array}$ & $\begin{array}{c}q_{\mathrm{c}, \mathrm{M} / \mathrm{air}} \\
\left(\AA^{-1}\right)^{* * *}\end{array}$ & $\begin{array}{c}q_{\mathrm{c}, \mathrm{M} / \mathrm{el}} \\
\left(\AA^{-1}\right)^{* * *}\end{array}$ \\
\hline $\begin{array}{c}1 \mathrm{M} \mathrm{LiPF}_{6} \\
\mathrm{EC} / \mathrm{DMC}(1: 1\end{array}$ & 1.2 & 0.38 & 0.023 & - \\
$\mathrm{v} / \mathrm{v})$ & & & \\
$\mathrm{NiO}$ & 6.67 & 1.97 & 0.053 & 0.047 \\
$\mathrm{Ni}$ & 8.90 & 2.60 & 0.061 & 0.056 \\
$\mathrm{Li}_{2} \mathrm{O}$ & 2.01 & 0.57 & 0.028 & 0.017 \\
sapphire & 3.97 & 1.18 & 0.041 & 0.034 \\
\hline
\end{tabular}

${ }^{*}$ To a very good approximation, these tabulated values are independent of incident photon energy. More specifically, at $E=20.00 \mathrm{keV}$ anomalous dispersion only has a significant effect on the $\rho_{\mathrm{e}}$ and $q_{\mathrm{c}}$ values for the $\mathrm{Ni}$ and $\mathrm{NiO}$ layers. This is less than a $1 \%$ effect and has been included in the calculations. ${ }^{* *}$ The electron density, $\rho_{\mathrm{e}}$, of each layer was calculated from the atomic composition of the compound according to the relationship: $\rho_{e}=\sum_{i} Z_{i} \cdot \rho \cdot N_{A} / M$. Here $Z_{\mathrm{i}}$ is the "effective" number of electrons in the $i^{\text {th }}$ atom. The summation is carried out over all atoms in the molecular formula for the compound. $N_{A}$ is Avogadro's number, $M$ is the molecular mass of the compound, and $\rho$ is the mass density of the compound. ${ }^{* * *}$ The critical momentum transfer values, $q_{\mathrm{c}, \mathrm{M} / \text { air }}$ for a given material $\mathrm{M}$ at the material (M)/air 
interface were calculated as $q_{c, \text { M/air }}=0.0375 \sqrt{\rho_{e}} \cdot{ }^{\mathrm{S} 1}$ The critical $q_{\mathrm{c}, \mathrm{M} / \mathrm{el}}$ at the material/electrolyte interfaces for in-operando experiment were thereby calculated as $q_{c, M / e l}=\sqrt{q_{c, M / a i r}^{2}-q_{c, e l / a i r}^{2}}$. This takes into account the transmission geometry of the electrochemical cell used in the XRR measurements and is an expectation for the critical angles observed in Figure 3.

The parameters used in the profiles obtained by the best fits of X-ray reflectivity (XRR) data are given in Tables S2a-g.

Table S2a. $\mathrm{E}=3.0$ (open circuit conditions)

\begin{tabular}{cccc}
\hline $\begin{array}{c}\text { Layer } \\
\text { relative to surface }\end{array}$ & $\begin{array}{c}\text { Thickness } \\
(\AA)\end{array}$ & $\begin{array}{c}\text { Electron density } \\
\rho_{\mathrm{e}}\left(\mathrm{e}^{-} \AA^{-3}\right)\end{array}$ & $\begin{array}{c}\text { Roughness } \\
(\AA)\end{array}$ \\
\hline Electrolyte & - & 0.38 & - \\
1 & 55.2 & 2.04 & 5.2 \\
2 & 16.9 & 2.59 & 2.7 \\
3 & 57.9 & 2.04 & 2.5 \\
4 & 15.7 & 2.59 & 2.6 \\
5 & 59.2 & 2.04 & 2.4 \\
6 & 17.4 & 2.59 & 2.1 \\
7 & 61.9 & 2.04 & 1.9 \\
8 & 16.4 & 2.59 & 2.1 \\
9 & 58.0 & 2.04 & 2.2 \\
10 & 18.4 & 2.59 & 2.3 \\
Substrate & - & 1.18 & 1.5 \\
\hline
\end{tabular}


Table S2b. $E=0.6 \mathrm{~V}+0.5 \mathrm{~h}$

\begin{tabular}{cccc}
\hline $\begin{array}{c}\text { Layer } \\
\text { relative to surface }\end{array}$ & $\begin{array}{c}\text { Thickness } \\
(\AA)\end{array}$ & $\begin{array}{c}\text { Electron density } \\
\rho_{\mathrm{e}}\left(\mathrm{e}^{-} \AA^{-3}\right)\end{array}$ & $\begin{array}{c}\text { Roughness } \\
(\AA)\end{array}$ \\
\hline Electrolyte & - & 0.38 & - \\
1 & 116.2 & 1.07 & 12.0 \\
2 & 23.4 & 2.59 & 3.4 \\
3 & 117.7 & 1.10 & 4.3 \\
4 & 22.3 & 2.59 & 3.7 \\
5 & 120.7 & 1.09 & 4.0 \\
6 & 16.9 & 2.59 & 3.2 \\
7 & 63.6 & 1.85 & 3.2 \\
8 & 15.9 & 2.59 & 1.9 \\
9 & 61.5 & 1.98 & 1.9 \\
10 & 16.8 & 2.59 & 3.0 \\
Substrate & - & 1.18 & 1.5 \\
\hline
\end{tabular}

Table S2c. $E=0.6 \mathrm{~V}+2.5 \mathrm{~h}$

\begin{tabular}{cccc}
\hline $\begin{array}{c}\text { Layer } \\
\text { relative to surface }\end{array}$ & $\begin{array}{c}\text { Thickness } \\
(\AA)\end{array}$ & $\begin{array}{c}\text { Electron density } \\
\rho_{\mathrm{e}}\left(\mathrm{e}^{-} \AA^{-3}\right)\end{array}$ & $\begin{array}{c}\text { Roughness } \\
(\AA)\end{array}$ \\
\hline Electrolyte & - & 0.38 & - \\
1 & 134.3 & 1.06 & 18.9 \\
2 & 21.9 & 2.59 & 1.2 \\
3 & 117.7 & 1.08 & 1.1 \\
4 & 16.6 & 2.59 & 3.9 \\
5 & 109.0 & 1.10 & 3.7 \\
6 & 20.4 & 2.59 & 3.1 \\
7 & 101.6 & 1.22 & 2.6 \\
8 & 17.2 & 2.59 & 3.3 \\
9 & 94.7 & 1.26 & 4.1 \\
10 & 21.8 & 2.59 & 1.3 \\
Substrate & - & 1.18 & 1.5 \\
\hline
\end{tabular}


Table S2d. $E=0.6 \mathrm{~V}+3.5 \mathrm{~h}$

\begin{tabular}{cccc}
\hline $\begin{array}{c}\text { Layer } \\
\text { relative to surface }\end{array}$ & $\begin{array}{c}\text { Thickness } \\
(\AA)\end{array}$ & $\begin{array}{c}\text { Electron density } \\
\rho_{\mathrm{e}}\left(\mathrm{e}^{-} \AA^{-3}\right)\end{array}$ & $\begin{array}{c}\text { Roughness } \\
(\AA)\end{array}$ \\
\hline Electrolyte & - & 0.38 & - \\
1 & 144.9 & 0.99 & 13.7 \\
2 & 21.2 & 2.59 & 2.1 \\
3 & 106.3 & 1.11 & 2.4 \\
4 & 20.2 & 2.59 & 4.4 \\
5 & 122.5 & 1.24 & 3.2 \\
6 & 16.3 & 2.59 & 4.1 \\
7 & 128.5 & 1.15 & 4.2 \\
8 & 19.1 & 2.59 & 3.3 \\
9 & 112.8 & 1.08 & 4.2 \\
10 & 22.2 & 2.59 & 1.4 \\
Substrate & - & 1.18 & 1.5 \\
\hline
\end{tabular}

Table S2e. $\mathrm{E}=0.6 \mathrm{~V}+4.0 \mathrm{~h}$

\begin{tabular}{cccc}
\hline $\begin{array}{c}\text { Layer } \\
\text { relative to surface }\end{array}$ & $\begin{array}{c}\text { Thickness } \\
(\AA)\end{array}$ & $\begin{array}{c}\text { Electron density } \\
\rho_{\mathrm{e}}\left(\mathrm{e}^{-} \AA^{-3}\right)\end{array}$ & $\begin{array}{c}\text { Roughness } \\
(\AA)\end{array}$ \\
\hline Electrolyte & - & 0.38 & - \\
1 & 173.5 & 0.99 & 25.0 \\
2 & 17.3 & 2.59 & 4.1 \\
3 & 112.3 & 1.03 & 3.6 \\
4 & 22.7 & 2.59 & 3.2 \\
5 & 120.6 & 1.18 & 3.9 \\
6 & 21.8 & 2.59 & 2.7 \\
7 & 124.6 & 1.13 & 3.7 \\
8 & 21.9 & 2.59 & 3.0 \\
9 & 115.8 & 1.10 & 3.8 \\
10 & 22.0 & 2.59 & 2.2 \\
Substrate & - & 1.18 & 1.5 \\
\hline
\end{tabular}


Table S2f. $E=0.6 \mathrm{~V}+4.5 \mathrm{~h}$

\begin{tabular}{cccc}
\hline $\begin{array}{c}\text { Layer } \\
\text { relative to surface }\end{array}$ & $\begin{array}{c}\text { Thickness } \\
(\AA)\end{array}$ & $\begin{array}{c}\text { Electron density } \\
\rho_{\mathrm{e}}\left(\mathrm{e}^{-} \AA^{-3}\right)\end{array}$ & $\begin{array}{c}\text { Roughness } \\
(\AA)\end{array}$ \\
\hline Electrolyte & - & 0.38 & - \\
1 & 150.1 & 0.99 & 15.0 \\
2 & 19.7 & 2.59 & 3.6 \\
3 & 116.2 & 1.02 & 3.9 \\
4 & 25.6 & 2.59 & 3.7 \\
5 & 118.3 & 1.08 & 4.4 \\
6 & 23.9 & 2.59 & 3.6 \\
7 & 122.7 & 1.08 & 4.0 \\
8 & 21.5 & 2.59 & 4.6 \\
9 & 119.0 & 1.10 & 4.2 \\
10 & 22.2 & 2.59 & 2.2 \\
Substrate & - & 1.18 & 1.5 \\
\hline
\end{tabular}

Table S2g. $\mathrm{E}=0.6 \mathrm{~V}+5.0 \mathrm{~h}$

\begin{tabular}{cccc}
\hline $\begin{array}{c}\text { Layer } \\
\text { relative to surface }\end{array}$ & $\begin{array}{c}\text { Thickness } \\
(\AA)\end{array}$ & $\begin{array}{c}\text { Electron density } \\
\rho_{\mathrm{e}}\left(\mathrm{e}^{-} \AA^{-3}\right)\end{array}$ & $\begin{array}{c}\text { Roughness } \\
(\AA)\end{array}$ \\
\hline Electrolyte & - & 0.38 & - \\
1 & 146.4 & 1.00 & 14.3 \\
2 & 21.5 & 2.59 & 3.3 \\
3 & 116.8 & 1.03 & 3.9 \\
4 & 26.4 & 2.59 & 3.4 \\
5 & 119.9 & 1.08 & 4.8 \\
6 & 23.8 & 2.59 & 3.6 \\
7 & 122.4 & 1.08 & 4.2 \\
8 & 21.5 & 2.59 & 4.0 \\
9 & 120.0 & 1.12 & 3.5 \\
10 & 22.5 & 2.59 & 2.6 \\
Substrate & - & 1.18 & 2.0 \\
\hline
\end{tabular}




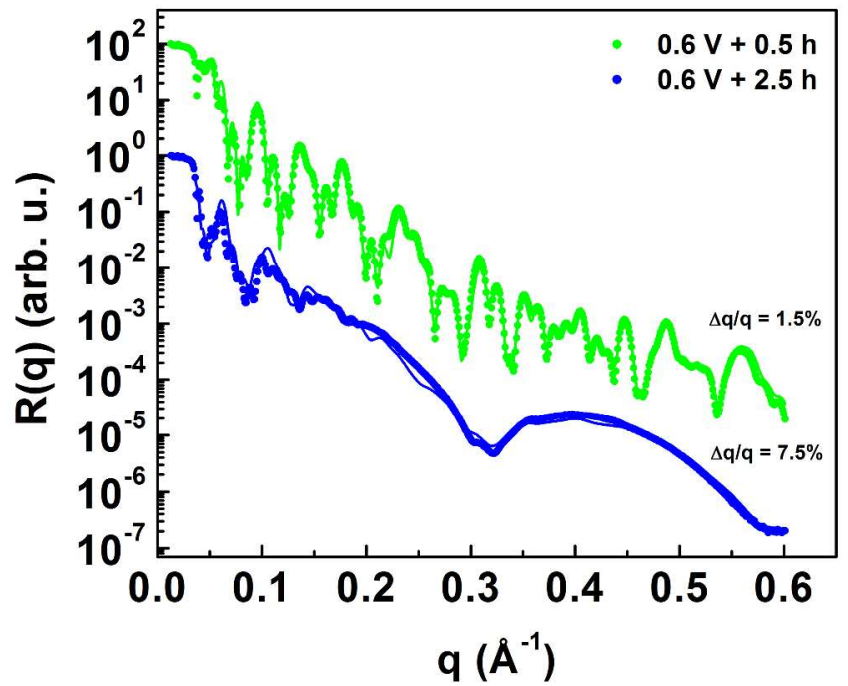

Figure S1. XRR data (solid circles) and best fits (solid lines) for a 5-bilayer $\mathrm{Ni} / \mathrm{NiO}$ film during Li-ion insertion at the early stage of lithiation. The curves are shifted vertically for clarity.

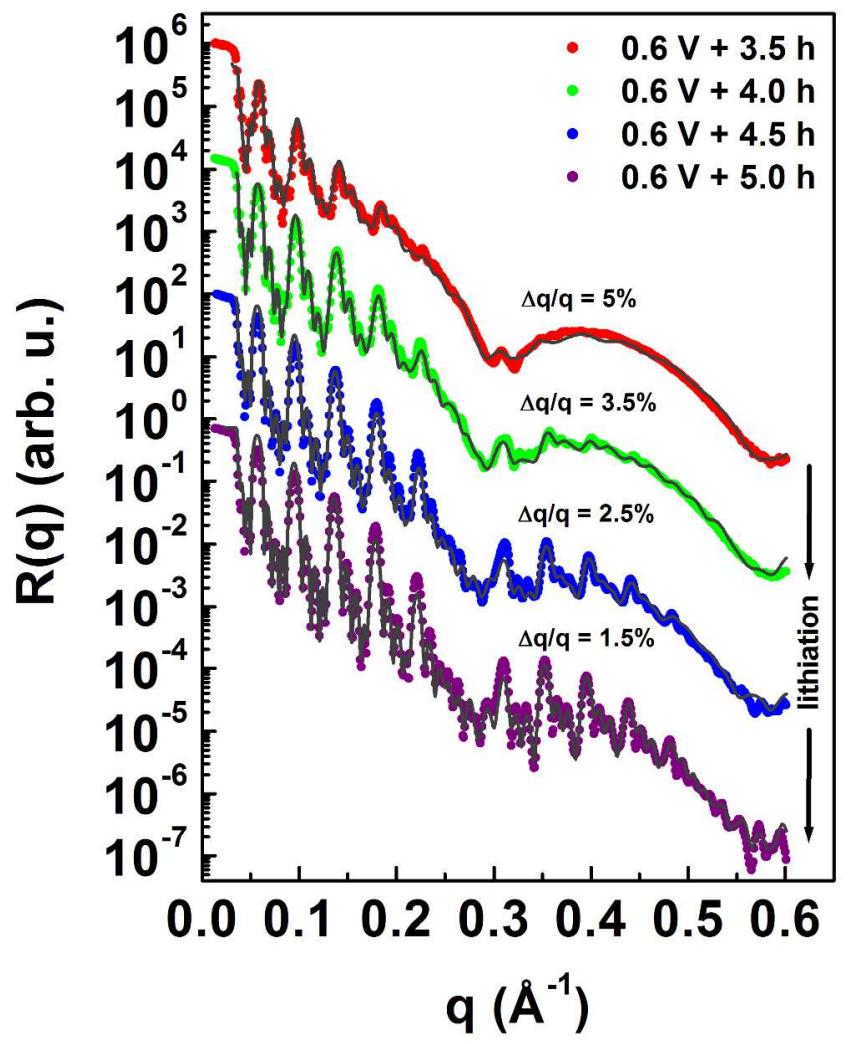

Figure S2. XRR data (solid circles) and best fits (solid lines) for 5-bilayer $\mathrm{Ni} / \mathrm{NiO}$ at the later stage of lithiation. The curves are shifted vertically for clarity. 


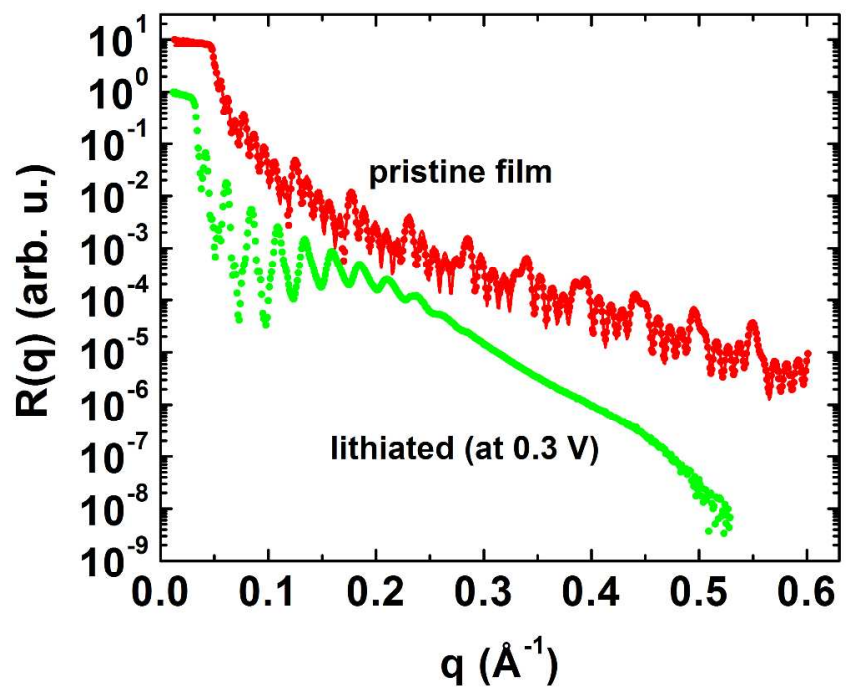

Figure S3. XRR data (solid circles) for pristine and lithiated 5-bilayer Ni/NiO (10 $\AA$ / $105 \AA)$ film. The solid line shown is the best fit to the data for the pristine film. The curves are shifted vertically for clarity.

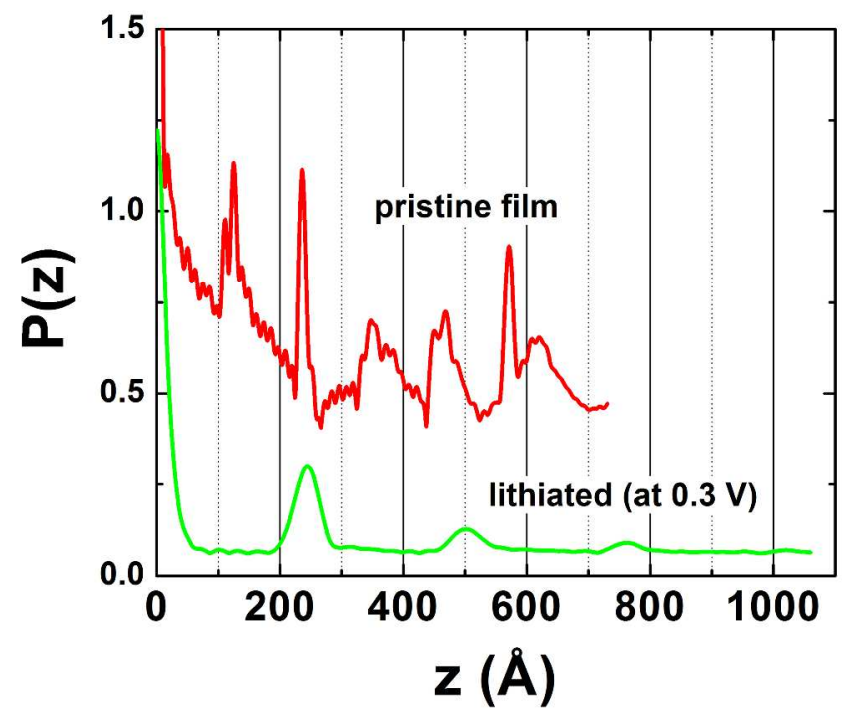

Figure S4. Patterson functions from the observed XRR data for the 5-bilayer Ni/NiO (10 $\AA$ / $105 \AA)$ film, presented in Figure S3, shifted vertically for clarity. 

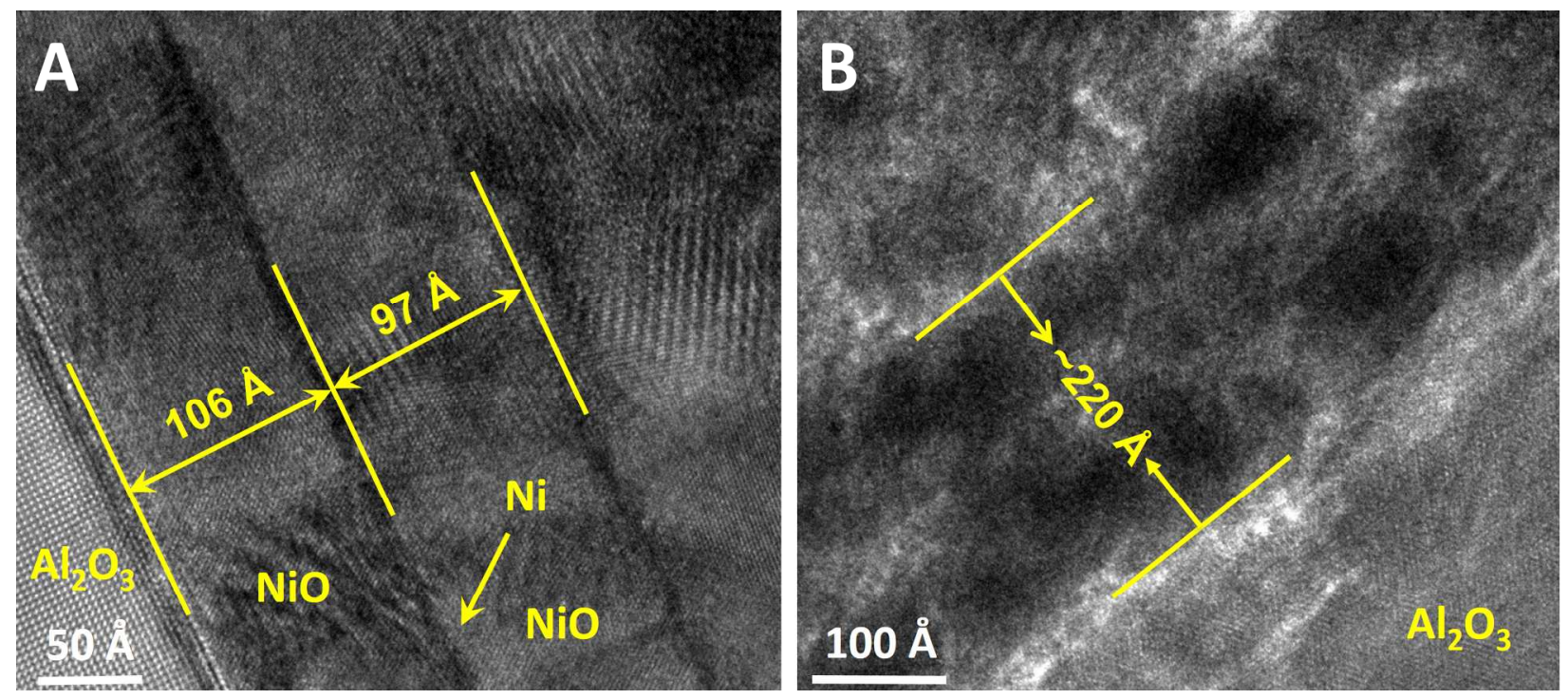

Figure S5. High resolution cross-sectional TEM images of the pristine (A) and the lithiated (B) 5-bilayer $\mathrm{Ni} / \mathrm{NiO}(10 \AA / 105 \AA)$ film near the sapphire substrate (the darker contrast represents heavier elements).

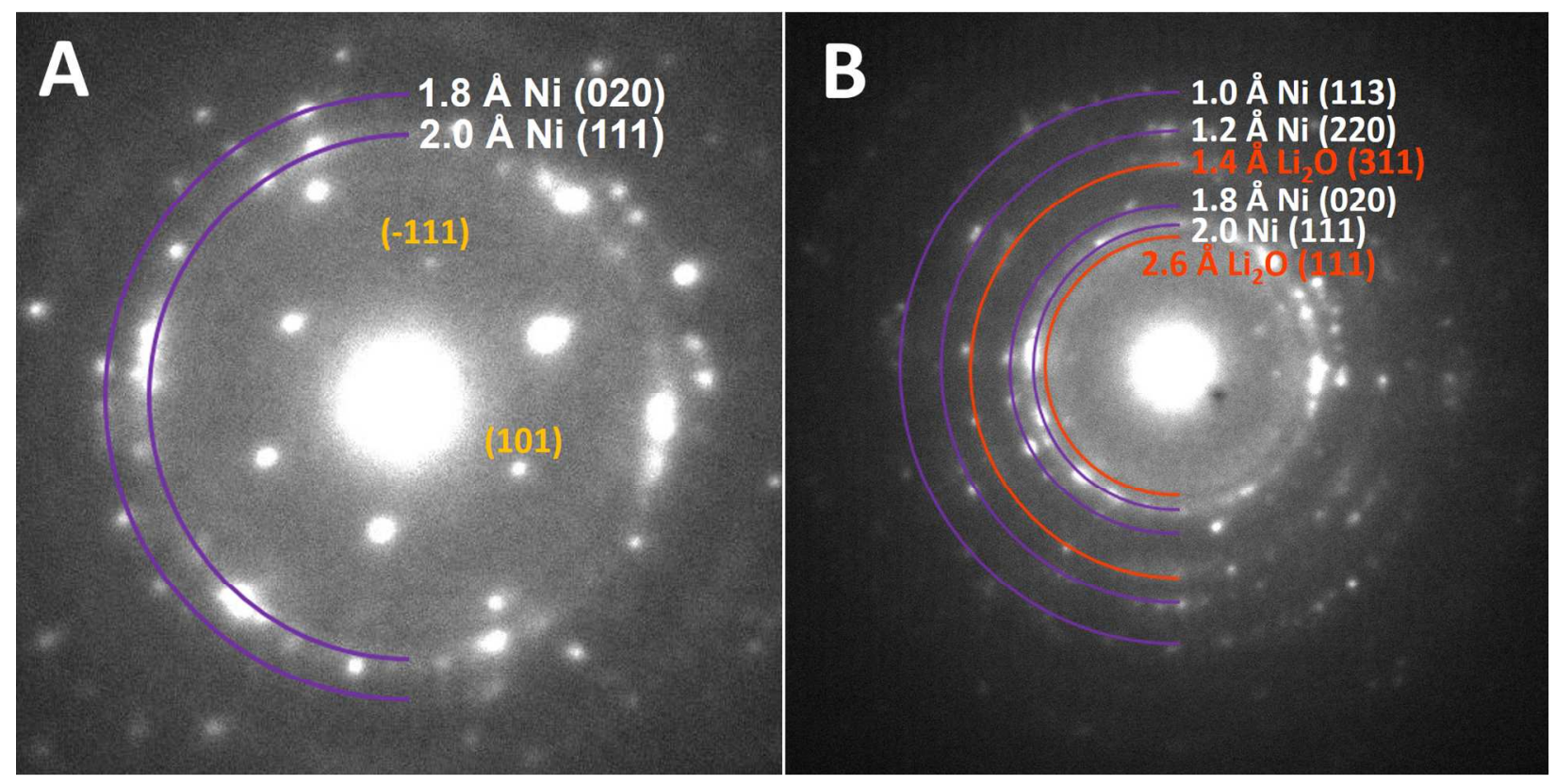

Figure S6. (A) Nano-beam electron diffraction pattern taken from the lithiated 5-bilayer Ni/NiO (10 $\AA$ / $105 \AA$ ) film near the $\mathrm{Al}_{2} \mathrm{O}_{3}$ substrate, in which the $\mathrm{Li}_{2} \mathrm{O}$ diffraction rings are weak. (B) Nano-beam diffraction pattern taken from the lithiated layers showing clearly the diffraction rings of $\mathrm{Li}_{2} \mathrm{O}$. The measured $d$-spacing of the rings with unit of angstrom and its corresponding lattice planes are labeled.

\section{References}

(S1) X-Ray and Neutron Reflectivity: Principles and Applications. Daillant, J., Gibaud, A. (Ed.), Springer-Verlag: Berlin, 1999, p. 93. 